Chronic Obstructive Pulmonary Diseases: Journal of the COPD Foundation

\author{
Original Research
}

\title{
Correlation Between Emphysema and Lung Function in Healthy Smokers and Smokers With COPD
}

Laura H. Thomsen, MD, PhD ${ }^{1}$ Saher B. Shaker, MD, $\mathrm{PhD}^{1}$ Asger Dirksen, DMSci ${ }^{1}$ Jesper H. Pedersen ${ }^{2}$ Ruth Tal-Singer, MD, $\mathrm{PhD}^{3}$ Per Bakke, DMSci ${ }^{4}$ Jørgen Vestbo, DMSci ${ }^{1,5}$

\section{Abstract}

Background: Emphysema is an important component of COPD; however, in previous studies the correlation between airflow limitation (AFL) and computed tomography (CT) lung density as a surrogate for emphysema has varied. We hypothesised a good correlation between lung function (forced expiratory volume in first second $\left[F E V_{1}\right]$ ) and emphysema (15th percentile density [PD 15]) and that this correlation also exists between loss of lung tissue and decline in lung function even within the time frame of longitudinal studies of relatively short duration. Methods: We combined 2 large longitudinal studies (the Danish Lung Cancer Screening Trial [DLCST] and the Evaluation of COPD Longitudinally to Identify Predictive Surrogate Endpoints [ECLIPSE]) of smokers or former smokers, with a wide range of AFL and CT lung density, and analysed data from 2148 participants who did not change smoking habits and who had at least $2 \mathrm{CT}$ scans and $2 \mathrm{FEV}_{1}$ measurements at least 3 years apart.

Results: Baseline correlation between $\mathrm{FEV}_{1}$ and PD15 was high ( $\mathrm{r}=0.716$, 95\% confidence interval [CI]: 0.694$0.736, p<0.001)$ indicating that at least half of the variation in $\mathrm{FEV}_{1}$ can be explained by variation in $\mathrm{CT}$ lung density. Correlation between the decline in FEV1 and progression of PD15 was considerably weaker $(r=0.081$, 95\% CI: 0.038-0.122, $p<0.001$ ).

Conclusions: Correlation is very high between lung density and lung function in a broad spectrum of smokers and ex-smokers. In contrast, the temporal associations (slopes) are weakly correlated, probably due to uncertainty in the estimation of slopes within a time frame of 3-4 years.

\begin{abstract}
Abbreviations: airflow limitation, $\mathbf{A F L}$; computed tomography, CT; forced expiratory volume in first second, $\mathbf{F E V}_{\mathbf{1}}$; the density point at which 15\% of lung voxels have a lower lung density, PD15; Danish Lung Cancer Screening Trial, DLCST; Evaluation of COPD Longitudinally to Identify Predictive Surrogate Endpoints, ECLIPSE; confidence interval, CI; forced vital capacity, FVC; Global initiative for chronic Obstructive Lung Disease, GOLD; total lung volume, TLV; Hounsfield units, HU

Funding Support: DLCST was funded in full by the Danish Ministry of Interior and Health. ECLIPSE was funded by GlaxoSmithKline. Dr. Thomsen received an unrestricted grant from The Danish Lung Association.

Date of Acceptance: March 20, 2015

Citation: Thomsen LH, Shaker SB, Dirksen A, et al. Correlation between emphysema and lung function in healthy smokers and smokers with COPD. J COPD F. 2015. 2(3): 204-213. doi: http://dx.doi.org/10.15326.jcopdf.2.3.2014.0154.
\end{abstract}

\section{This article contains an online supplement}

(names of members of the ECLIPSE steering and scientific committees and the study investigators).

1 Department of Respiratory Medicine, Gentofte Hospital, University of Copenhagen, Denmark

2 Department of Cardiothoracic Surgery, University of Copenhagen, Denmark

3 GlaxoSmithKline, King of Prussia, Pennsylvania
4 Department of Clinical Science, University of Bergen, and Department of Thoracic Medicine, Haukeland University Hospital, Bergen, Norway

5 Respiratory and Allergy Research Group, Manchester Academic Health Science Centre, University Hospital South Manchester; NHS Foundation Trust, Manchester, United Kingdom 


\section{Address correspondence to:}

Laura H. Thomsen, MD, PhD

Phone:+45 40844080

laurahohwu@gmail.com

\section{Keywords:}

chronic obstructive pulmonary disease; COPD; CT lung density; PD15; lung function; smoking

\section{Introduction}

Chronic obstructive pulmonary disease (COPD) is a leading cause of morbidity and mortality; it was the third ranking cause of death in 2010., ${ }^{1,2}$ COPD is defined by abnormal lung function, which was first described by Tiffeneau in 1947, ${ }^{3,4}$ and the conventional method for monitoring the progression of COPD is by serial measurements of forced expiratory volume in first second $\left(\mathrm{FEV}_{1}\right){ }^{5}$ An important component of COPD is pulmonary emphysema, which is defined morphologically as loss of alveolar tissue. ${ }^{6}$ In the 1970's Hounsfield developed computed tomography (CT) for clinical use and emphysema was first described by CT in the late 1970's and early 1980's. ${ }^{7,8}$ Emphysema can be quantified using $\mathrm{CT},{ }^{9-11}$ and the strong correlation between CT densitometry scores and quantitative pathology scores of emphysema ${ }^{12-14}$ makes it possible to non-invasively follow the progression of emphysema by repeat $\mathrm{CT}$ scans.

Numerous previous studies have investigated the relationship between CT lung density and lung function with varying results. ${ }^{15}$ Most of these studies were based on small and more selected populations with a limited range of lung functions and densities which may explain poor correlations and it is not surprising that previous cross-sectional studies have shown varying degrees of correlation between CT quantification of emphysema and airflow obstruction in COPD. ${ }^{15-19}$ However, it is an accepted fact that some patients with severe emphysema have remarkably little airflow obstruction, ${ }^{20,21}$ and at the same time other patients with severe airflow obstruction have strikingly normal lungs on visual inspection of their CT scans; this is usually interpreted as evidence of distinct phenotypes of COPD. ${ }^{22,23}$ Furthermore, it has been difficult in prospective, longitudinal studies to show a good correlation between loss of CT lung density and decline in lung function in patients with COPD. ${ }^{24}$

With the aim of studying the correlation between emphysema and lung function in smokers, we combined 2 large cohorts of smokers and former smokers with a wide range of airflow obstruction, and we hypothesised that there would be a good correlation between lung function and emphysema and that this correlation also would be found between CT evidence of loss of lung tissue and decline in lung function $\left(\mathrm{FEV}_{1}\right)$ even within the time frame of longitudinal studies of relatively short duration.

\section{Material and Methods}

\section{Study Population}

The current paper presents a pooled analysis of lung function and CT data from participants in 2 studies: the Danish Lung Cancer Screening Trial (DLCST) and the Evaluation of COPD Longitudinally to Identify Predictive Surrogate Endpoints (ECLIPSE). We included data from participants who did not change smoking habits while participating in the studies and who had at least $2 \mathrm{CT}$ scans and at least $2 \mathrm{FEV}_{1}$ measurements at least 3 years apart.

From DLCST, ${ }^{25}$ we included participants randomized to annual CT scans. DLCST is a single-center 4-year trial investigating the effect of screening on lung cancer mortality. Individuals volunteered to the trial in response to advertisements in local free newspapers. A total of 4104 participants were randomized to either annual screening with low dose CT or no screening (control group). Participants were 50-70 years of age without lung cancer-related symptoms. They had to be current or ex-smokers with a minimum of 20 pack years, and an $\mathrm{FEV}_{1}$ of at least $30 \%$ of predicted normal at baseline. Ex-smokers had to have quit after the age of 50 years and less than 10 years before inclusion. In the screening arm, 2052 volunteers were scanned annually 5 times. In addition, at the annual visits for all participants spirometry was performed, smoking habits were recorded and the carbon monoxide level in exhaled breath was measured.

In ECLIPSE, ${ }^{26,27}$ patients with COPD who were between the ages of 40 and 75 years were enrolled in the study if they had a history of 10 or more pack years of smoking, as well as an $\mathrm{FEV}_{1}$ less than $80 \%$ of the predicted normal value and a ratio of $\mathrm{FEV}_{1}$ to forced vital capacity (FVC) of 0.7 or less. After the baseline visit, patients returned to their study centers on 7 occasions for follow-up assessments: at 3 months and at 6 months and then every 6 months for 3 years. At each visit, patients reported smoking habits and the severity of COPD was graded according to the stages of disease as defined by the Global initiative for chronic 
Obstructive Lung Disease (GOLD). ${ }^{28} \mathrm{CT}$ scans were performed at baseline and after 1 and 3 years.

Both studies were conducted according to the Declaration of Helsinki and Good Clinical Practice guidelines. All participants provided written informed consent, and the studies were approved by the relevant ethics and review boards and registered at ClinicalTrials.gov. (DLCST: NCT00496977, ECLIPSE: NCT00292552).

\section{Lung Function Testing}

Spirometry was performed by professionally trained and experienced hospital-based pulmonary function technicians or nurses; equipment calibration was performed daily and checked prior to each test, and the flow sensor was cleaned daily, according to manufacturer's recommendations.

Measurements included FEV 1 and FVC and their ratio (FEV $1 / F V C)$. Both $F E V_{1}$ and FVC were expressed in absolute values and as a percentage of predicted values according to European reference equations. ${ }^{29}$ Airflow limitation (AFL) was defined as $\mathrm{FEV}_{1} / \mathrm{FVC}<0.7$. The severity of AFL was classified according to GOLD. ${ }^{28}$

In DLCST, spirometry was performed annually for 4 years using a computerized system (Spirotrac IV software; Fleich Pneumotach model 6800, Vitalograph, Buckingham, UK). No bronchodilatation was applied.

In ECLIPSE, spirometry was measured at baseline and at each subsequent visit; patients underwent spirometry (Viasys MasterScope) 15 minutes after inhaling $400 \mu \mathrm{g}$ of salbutamol from a metered-dose inhaler with the use of a Volumatic spacer (GlaxoSmithKline).

\section{CT Scans}

The CT protocols were quite similar in DLCST and ECLIPSE. In both studies scans were acquired at suspended full inspiration without administration of intravenous contrast, and both used multi-slice low-dose technique ( $120 \mathrm{kV}$ and $40 \mathrm{mAs}$ ) and a $512 \mathrm{X} 512$ matrix. Reconstruction algorithms differed slightly. In DLCST, images were reconstructed with $3 \mathrm{~mm}$ slice thickness and $50 \%$ overlap using a soft reconstruction algorithm (Philips: kernel A), whereas in ECLIPSE, images were reconstructed using $1.0 \mathrm{~mm}$ (Siemens) or $1.25 \mathrm{~mm}$ (GE) contiguous slices and an intermediate spatial frequency reconstruction algorithm (GE: Standard, Siemens: b35f). In both studies, CT scanners were calibrated regularly using standard water calibration phantoms according to the manufacturers' recommendations at the individual centers.

\section{Image Analysis and Emphysema Quantification}

In both studies, image analysis was performed at a central laboratory, although the image analysis process differed slightly. In DLCST, scans were analyzed by the Image Group at the Department of Computer Science, University of Copenhagen (Denmark) using in-house developed software, ${ }^{30}$ and in ECLIPSE, scans were analyzed at the University of British Columbia using Pulmonary Workstation 2.0 software (VIDA Diagnostics, Coralville, Iowa, United States). ${ }^{31}$

The total lung volume (TLV) was calculated by summing the CT voxels that contained lung. The frequency distribution of the $\mathrm{x}$-ray attenuation values of the CT lung voxels was created, and the lung density at the lowest 15 th percentile point (PD15--the density point at which $15 \%$ of lung voxels have a lower lung density) was calculated. Subsequently, x-ray attenuation values in Hounsfield units (HU) were converted to density (g/l) by adding 1000 to the HU (e.g. PD 15 value of $-950 \mathrm{HU}$ equals $50 \mathrm{~g} / \mathrm{l})$. The lower the PD 15 values in $\mathrm{g} / \mathrm{l}$ (i.e., closer to 0 ), the more emphysema is present. This method of emphysema quantification has been validated against pathology ${ }^{14}$ and has been applied in several studies. ${ }^{32-34}$ We preferred the percentile density instead of the low attenuation area percentage below -950 HU because percentile densities are more appropriate for following the progression of emphysema. ${ }^{9,35} \mathrm{CT}$ lung density is very sensitive to the level of inspiration during the scan, which more than doubles from full inspiration to full expiration; therefore, we corrected PD15 for lung volume by physiologic modeling using the sponge model, ${ }^{36}$ and lung density is expressed as the volume-adjusted PD15 throughout this paper. 24,37

\section{Statistical Analysis}

For each participant, the annual loss of CT lung density (PD15) and decline in lung function (FEV 1 ) were calculated as slopes in regression models with time as explanatory variable. The correlation between decline in lung function and lung density was calculated as the Pearson correlation coefficient (and 95\% confidence interval) of these slopes. Data are presented as mean and standard deviations where appropriate. All tests were 2-sided, for which an alpha level of 0.05 was considered to indicate statistical significance. 


\section{Results}

\section{Baseline Characteristics}

A total of 2148 participants were included in the

analysis; 1178 from DLCST and 970 from ECLIPSE. The baseline characteristics are shown in Table 1. Participants in DLCST were younger and had smoked fewer pack years, and more were females and current

\section{Table 1: Characteristics of the Participants at Baseline}

\begin{tabular}{|c|c|c|c|c|}
\hline \multicolumn{2}{|c|}{ 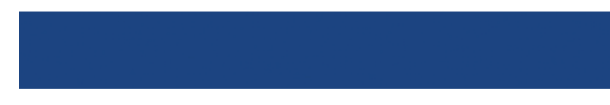 } & DLCST & ECLIPSE & \multirow{2}{*}{$\begin{array}{c}\text { p-value } \\
<0.001\end{array}$} \\
\hline Males/Femal & & $658 / 520$ & $623 / 347$ & \\
\hline Age & years (range) & $58(49-71)$ & $63(40-76)$ & $<0.001$ \\
\hline Pack Years & years (range) & $36(20-174)$ & $46(6-205)$ & $<0.001$ \\
\hline \multirow{2}{*}{ Smoking } & Former & 357 & 676 & \multirow{2}{*}{$<0.001$} \\
\hline & Current & 821 & 294 & \\
\hline \multirow{5}{*}{$\begin{array}{l}\text { Spirometric } \\
\text { GOLD Stage }\end{array}$} & 0 & 687 & 0 & \multirow{5}{*}{$<0.001$} \\
\hline & I & 317 & 0 & \\
\hline & II & 159 & 471 & \\
\hline & III & 15 & 391 & \\
\hline & IV & 0 & 108 & \\
\hline $\mathrm{FEV}_{1} \%$ & mean $(S D)$ & $94(17)$ & $50(15)$ & $<0.001$ \\
\hline Predicted & decline (SD) \%/year & $-2.4(1.9)$ & $-1.3(2.4)$ & $<0.001$ \\
\hline
\end{tabular}

\begin{tabular}{lllll}
\hline Adjusted & decline (SD) HU/year & $-1.05(1.58)$ & $-1.06(2.20)$ & 0.896 \\
\hline \hline
\end{tabular}

smokers. More importantly, DLCST participants had less AFL and less emphysema (denser lungs) compared to patients from ECLIPSE. However, decline in lung function was steeper in DLCST, and loss of CT lung density was similar in both cohorts.

\section{Correlations}

At baseline the correlations between $\mathrm{FEV}_{1}$ and $\mathrm{PD} 15$ were highly significant $\quad(p<0.001)$ in both cohorts, and when the cohorts were combined the coefficient reached 0.716 (0.694-0.736) indicating that approximately half of the variation in $\mathrm{FEV}_{1}$ can be explained by variation in $\mathrm{CT}$ lung density (Figure $1 \mathrm{~B}$ and Table 2). In subgroups with a restricted range of lung function (that is separate cohorts [DLCST and ECLIPSE],

\section{Figure 1. Baseline Correlations Between Lung Function $\left(F E V_{1}\right)$ and Emphysema (PD15)}

A

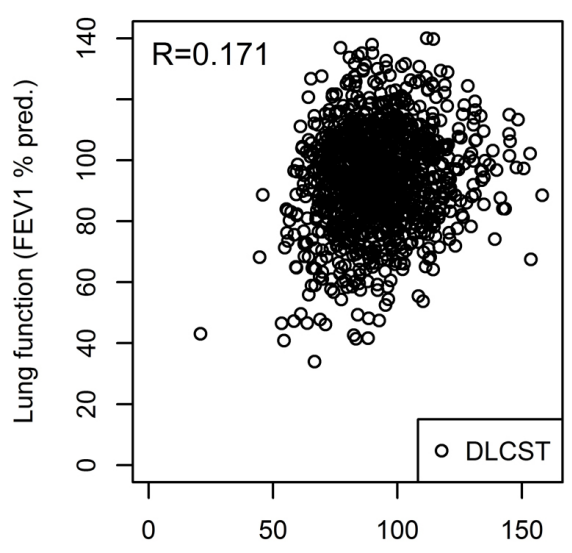

Volume adjusted 15th percentile density (g/L)
B

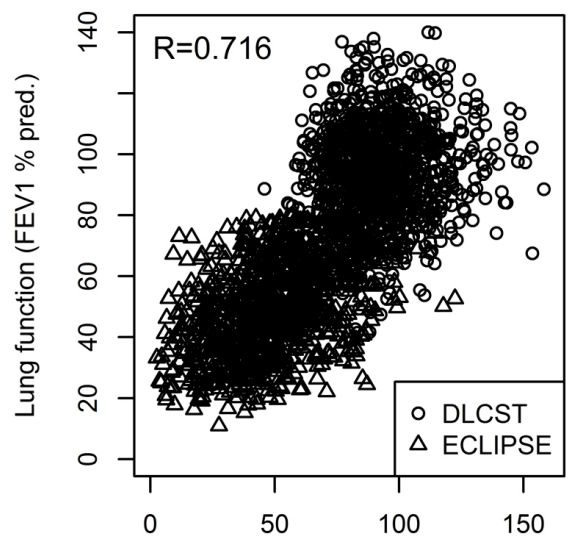

Volume adjusted 15th percentile density ( $g / L)$

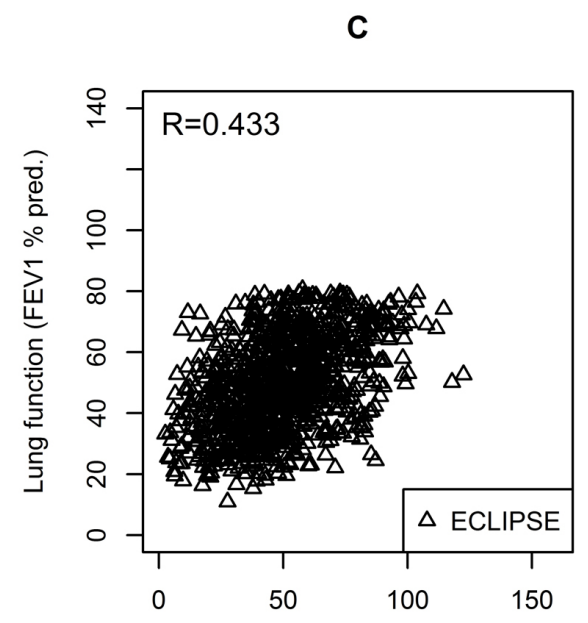

Volume adjusted 15th percentile density ( $\mathrm{g} / \mathrm{L}$ ) 


\title{
Table 2. Correlation Between FEV 1 and PD15 at Baseline and Decline in FEV 1 and PD15
}

\section{Subgroup}

n

\author{
Correlation Between p-value \\ FEV 1 and PD15 \\ at Baseline \\ ( $95 \%$ confidence interval)
}
Correlation Between p-value
Decline in FEV
and PD15
(95\% confidence interval)

\begin{tabular}{l|r|r|r|r|r|r}
\multirow{3}{*}{ Cohort } & DLCST & 1178 & $0.171(0.115-0.226)$ & $<\mathbf{0 . 0 0 1}$ & $0.044(-0.013-0.101)$ & 0.133 \\
\cline { 2 - 8 } & ECLIPSE & 970 & $0.433(0.381-0.483)$ & $<\mathbf{0 . 0 0 1}$ & $0.111(0.049-0.173)$ & $<\mathbf{0 . 0 0 1}$ \\
\hline \multirow{2}{*}{ Sex } & Male & 1281 & $0.735(0.709-0.759)$ & $<\mathbf{0 . 0 0 1}$ & $0.098(0.043-0.152)$ & $<\mathbf{0 . 0 0 1}$ \\
\cline { 2 - 8 } & Female & 867 & $0.707(0.672-0.739)$ & $<\mathbf{0 . 0 0 1}$ & $0.055(-0.012-0.121)$ & 0.105 \\
\hline \multirow{2}{*}{ Smoking } & Former & 1033 & $0.746(0.718-0.772)$ & $<\mathbf{0 . 0 0 1}$ & $0.037(-0.024-0.098)$ & 0.231 \\
\cline { 2 - 8 } & Current & 1115 & $0.600(0.561-0.636)$ & $<\mathbf{0 . 0 0 1}$ & $0.100(0.042-0.158)$ & $<\mathbf{0 . 0 0 1}$ \\
\hline \multirow{3}{*}{ Spirometric } & No & 687 & $0.056(-0.019-0.130)$ & $<0.144$ & $-0.061(-0.139-0.017)$ & 0.127 \\
\cline { 2 - 8 } GOLD stage & I & 317 & $0.047(-0.063-0.157)$ & $<0.400$ & $0.094(-0.019-0.204)$ & 0.105 \\
\cline { 2 - 8 } & II & 630 & $0.394(0.326-0.458)$ & $<\mathbf{0 . 0 0 1}$ & $0.112(0.037-0.185)$ & $\mathbf{0 . 0 0 3}$ \\
\hline All & III & 406 & $0.197(0.101-0.289)$ & $<\mathbf{0 . 0 0 1}$ & $0.167(0.070-0.260)$ & $<\mathbf{0 . 0 0 1}$ \\
\hline
\end{tabular}

\section{Figure 2.}

A

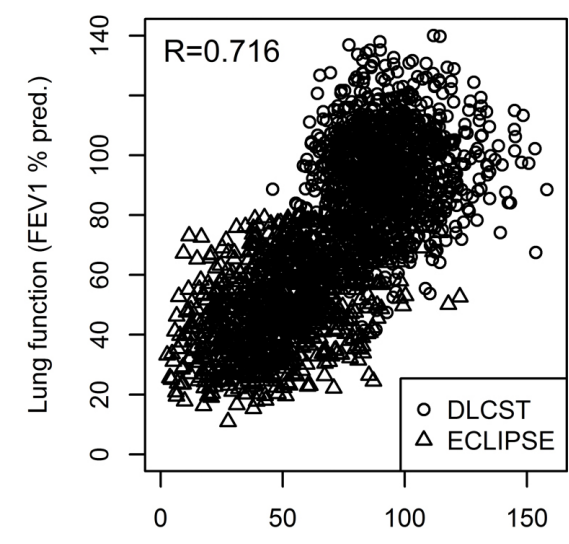

Volume adjusted 15th percentile density ( $g / L)$
B

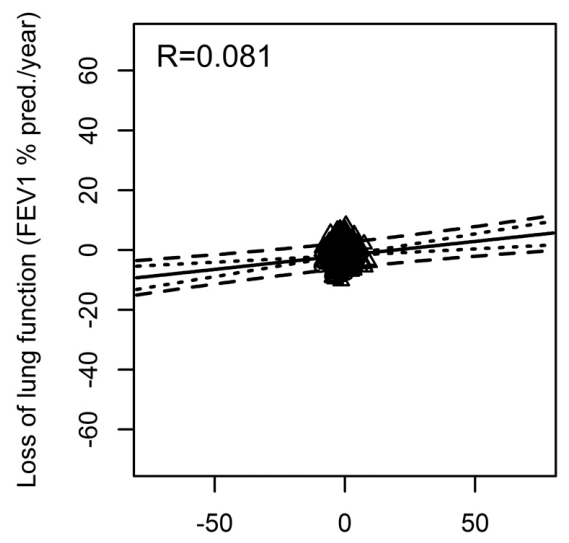

Loss of vol. adj. 15th percentile density (g/L/year)

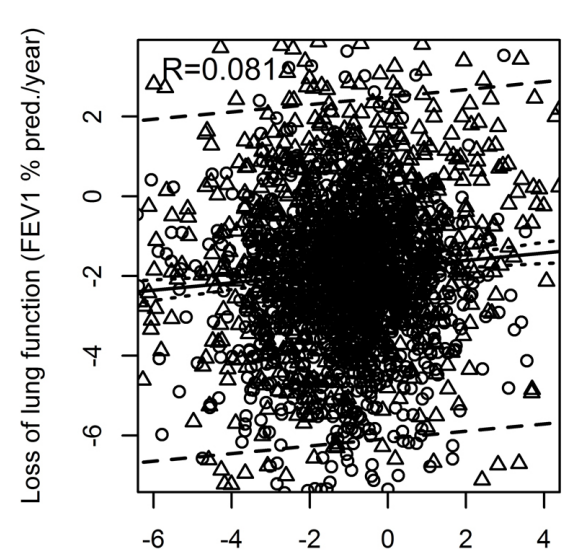

Loss of vol. adj. 15th percentile density (g/L/year)

A: Correlation between lung function $\left(\mathrm{FEV}_{1}\right)$ and emphysema (PD15).

B: Correlation between decline in lung function $\left(\mathrm{FEV}_{1}\right)$ and progression of emphysema (PD15) on same scale as $\mathrm{A}$.

C: Correlation between decline in lung function $\left(\mathrm{FEV}_{1}\right)$ and progression of emphysema (PD15) in close up.

In $\mathrm{B}$ and $\mathrm{C}$ lines indicate confidence (dotted) and prediction (dashed) bands.

and separate COPD stages) the correlation was weaker, however, in most cases still statistically significant.

The correlation between the slopes (decline in lung function $\left[\mathrm{FEV}_{1}\right]$ and progression of emphysema [PD 15]) appears in Table 2, Figure 2B and Figure 2C. Overall the correlation was weak $(\mathrm{r}=0.081$ [0.038- 
$0.122])$, although highly significant $(p<0.001)$. The correlations were generally stronger in subgroups with faster decline such as current smokers and patients with AFL. Among the latter, the correlation increased with decreasing lung function and reached 0.15 for GOLD stages III and IV.

\section{Discussion}

COPD is a disease that evolves over decades often with a substantial amount of emphysema and airflow obstruction at the time of diagnosis. In this large population of individuals at risk and patients with COPD, we found a good overall correlation between baseline CT lung density and $\mathrm{FEV}_{1}$ and at the same time a poor correlation between changes over time that is loss of CT lung density and decline in $\mathrm{FEV}_{1}$.

Ideally, the relationship between lung function and density should be studied in a large, unselected sample from the general population at a single center; however, this is not acceptable due to ethical issues related to exposing healthy individuals to the ionizing radiation of repeat CT scans, and in the real world single center studies are possible only in limited sample sizes. Realizing this, we decided to combine data from 2 large, observational studies with the aim of creating a unique sample covering the entire spectrum of COPD in heavy smokers, from individuals at risk of developing airflow limitation to patients with very severe COPD. In the 2 studies, CT was performed subsequent to inclusion, and participants were selected based on lung function only. Nevertheless, the combined sample not only covers a wide range of airflow limitation, but an equally wide range of CT lung densities and this is advantageous when studying the relationship between lung function and lung density. There is a risk of falsely inflating correlation when combining studies if any of the variables of interest reflects extremes; e.g., by combining super-healthy individuals and patients with very severe COPD. However, there is a significant overlap of both $\mathrm{FEV}_{1}$ and $\mathrm{PD} 15$ values in our cohorts as shown in Figure 1 and thus we do not think our findings are biased.

Computed tomography lung density is a surrogate for emphysema, and lung function measures airflow limitation as an indication of airways disease. Some investigators consider these 2 components of COPD as representing distinct and independent phenotypes. However, in our population (Figure 1B) the 2 components seem to be closely related, and we were not able to differentiate distinct phenotypes based on these characteristics. The CT measurements of lung density could play a more important role in the assessment of persons with COPD, but the results also show that quantitative measurements - at the current stage - are not precise enough to follow the progression of emphysema in individual patients and should not be used as such. Furthermore, currently available software cannot detect the heterogeneity and appearance of emphysema patterns (centrilobular, paraseptal and panlobular ${ }^{38}$ ) that most chest physicians are familiar with, and there is a need for more sophisticated information than just a measurement of overall lung density. Therefore, efforts have been put into developing unsupervised machine learning approaches to subtyping data. One recent example is the COPDGene Cluster analysis ${ }^{39}$ where data on quantitative chest $\mathrm{CT}$, spirometric and clinical measures from the COPDGene trial was used to find clinically relevant clusters. Four clusters were identified and associated with COPD-related clinical characteristics (i.e., exacerbation and dyspnea). The associations were replicated in a validation sample. The analysis of data was rather complex and the optimal selection of features for clustering is a critical area for the application of unsupervised learning. However, the acceptance of an interpretation depends on its intuitive appeal, and in this regard, there is more work needed before computer software can automatically detect distinct and intuitively meaningful subtypes in COPD. We cannot exclude that with more information (e.g., the distribution of emphysema, clinical characteristics [including exacerbations and dyspnea]) and genetic data, it would be possible to define more distinct clusters in our cohort.

Chest CT and lung density could very well be a powerful tool in educating patients about the harmful effects of smoking. Seeing their own lungs with highlighted regions of low attenuation areas could prove effective in motivating smoking cessation. The quitting rate rises and the motivation to quit increases when persons are informed about their lung age 40 and probably also if confronted with damage of their own lungs. Several studies have investigated smoking cessation in lung cancer screening trials ${ }^{41-43}$ and it was found that a screen-detected abnormality was associated with increased smoking cessation. This indicates that abnormalities on CT may serve as a strong catalyst for smoking cessation. 
Several previous studies have investigated the correlation between CT lung density and physiology with varying results. ${ }^{15}$ To our knowledge only 6 studies have examined the correlation between PD 15 and FEV 1 in percent of predicted and they found correlations ranging from $0.09-0.62 .{ }^{44-48}$ This is likely due to the fact that all of these studies were based on more selected populations with a limited range of airflow limitation and lung densities which may explain poor correlations.

We used simple Pearson correlation on both the baseline values and the slopes to compare the correlation between baseline values with the correlation between slopes in this large cohort, and refrained from using multiple correlations and more sophisticated statistical models and adjustments as these did not seem to add value given the aim of our study.

The poor correlation between decline in lung function $\left(F E V_{1}\right)$ and loss of lung density (PD15), the slopes, is probably explained by the relatively short time frames of the 2 studies (4 years for DLCST and 3 years for ECLIPSE). Within a time frame of 3-4 years the changes in both PD 15 and FEV 1 are relatively small as compared to the measuring error which for both parameters is larger than the annual change. ${ }^{37,49}$ This is illustrated in Figure 2 where baseline values (Figure 2A) and annual changes are plotted on the same scale (Figure 2B). The figure shows how small the annual changes are as compared to the changes that have accumulated at an age of 60 years which was the mean age of the participants.

An inherent limitation of pooled analyses is the expected differences in the inclusion criteria, study investigations and the way data are collected in the 2 studies, which may introduce selection bias. Nevertheless, this heterogeneity might be considered as an advantage, since the participants reflect 2 different but complementary populations. DLCST cohort is a screening cohort whereas ECLIPSE is a clinical cohort. Another source of selection bias can result from the exclusion of participants changing their smoking habits during the study; however, the exclusion is necessary due to the rapid fall in lung density following smoking cessation. $^{50,51}$ We only included smokers or former smokers in the analysis, and therefore, results cannot be extrapolated to never-smokers, however the risk of developing COPD in the Western hemisphere is greater in current and former smokers.

There are a few participants in the upper left corner of Figure 1B who have severe emphysema (PD15 <20 g/L) and almost no airflow limitation ( $\mathrm{FEV}_{1}>60 \%$ pred.), whereas the lower right corner of Figure $1 \mathrm{~B}$ is empty. Thus, no participants had low lung function $\left(\mathrm{FEV}_{1}<50 \%\right.$ pred.) without also having some degree of emphysema (PD15 < 100 g/L). Patients with asthma usually suffer from airflow limitation without loss of lung density, and the emptiness of the lower right corner is consistent with exclusion of patients diagnosed with asthma in ECLIPSE.

Lung function was measured with meticulousness in both studies but differs primarily, because the test was performed post bronchodilation in ECLIPSE and without bronchodilation in DLCST. We believe that this has negligible effect because ECLIPSE is a specialist center cohort and most of the participants were on standard of care, the opposite was true for the populationbased DLSCT cohort. CT protocols and image analysis software differed between DLCST and ECLIPSE, and CT quantification of emphysema is influenced by both scan parameters (such as slice thickness and reconstruction algorithm) and choice of software. However, previous studies of CT quantification of emphysema have shown minimal differences between results obtained with soft reconstruction (DLCST) and an intermediate spatial frequency reconstruction (ECLIPSE). ${ }^{52}$

In conclusion, we found a very high correlation between lung density and lung function using 2 cohorts covering a broad spectrum of smokers, ranging from healthy participants to patients with severe COPD. In contrast, the temporal associations (slopes) were weakly correlated, probably due to uncertainty in the estimation of slopes over the relatively short duration (3-4 years) of the 2 studies.

\section{Acknowledgements}

The authors thank the investigators and participants of the DLCST and ECLIPSE for their valuable contributions, and the study sites staff for performing all the assessments.

DLCST was funded in full by the Danish Ministry of Interior and Health. The Danish Ministry of Interior and Health had no influence on the study design, the collection, analysis and interpretation of data, on the writing of the report or in the decision to submit the paper. ECLIPSE was funded by GlaxoSmithKline, and the study was designed by a Steering Committee which consisted of members from both the academic field and the sponsor. Data from ECLIPSE was provided by the sponsor, but analyzed and interpreted by the authors of 
this report.

\section{Declaration of Interest}

LHT received an unrestricted grant from the Danish Lung Association. RTS is an employee of GlaxoSmithKline.

No other authors have conflicts of interest to declare. 


\section{References}

1. Lozano R, Naghavi M, Foreman K, et al. Global and regional mortality from 235 causes of death for 20 age groups in 1990 and 2010: a systematic analysis for the Global Burden of Disease Study 2010. Lancet. 2012;380(9859):2095-2128. doi: http://dx.doi.org/10.1016/S0140-6736(12)61728-0

2. LopezAD,Shibuya K, Rao C,etal.Chronicobstructivepulmonary disease: current burden and future projections. Eur Respir J. 2006;27(2):397-412. doi: http://dx.doi.org/10.1183/09031936.06.00025805

3. Yernault JC. The birth and development of the forced expiratory manoeuvre: a tribute to Robert Tiffeneau (1910-1961). Eur Respir J. 1997;10(12):2704-2710. doi: http://dx.doi.org/10.1183/09031936.97.10122704

4. Tiffeneau R, Pinelli A. Air circulant et air captif dans l'exploration de la fonction ventilatrice pulmonaire. Paris Med. 1947;37(52):624628.

5. Vestbo J, Edwards LD, Scanlon PD, et al. Changes in forced expiratory volume in 1 second over time in COPD. $N$ Engl $J$ Med. 2011;365(13):1184-1192.

doi: http://dx.doi.org/10.1056/NEJMoa1105482

6. The definition of emphysema. Report of a National Heart, Lung, and Blood Institute, Division of Lung Diseases workshop. Am Rev Respir Dis. 1985;132(1):182-185.

7. Rosenblum LJ, Mauceri RA, Wellenstein DE, Bassano DA, Cohen WN, Heitzman ER. Computed tomography of the lung. Radiology. 1978;129(2):521-524. doi: http://dx.doi.org/10.1148/129.2.521

8. Goddard PR, Nicholson EM, Laszlo G, Watt I. Computed tomography in pulmonary emphysema. Clin Radiol. 1982;33(4):379-387. doi: http://dx.doi.org/10.1016/S0009-9260(82)80301-2

9. Newell JD, Jr., Hogg JC, Snider GL. Report of a workshop: quantitative computed tomography scanning in longitudinal studies of emphysema. Eur Respir J. 2004;23(5):769-775. doi: http://dx.doi.org/10.1183/09031936.04.00026504

10. Dirksen A. Monitoring the progress of emphysema by repeat computed tomography scans with focus on noise reduction. Proc Am Thorac Soc. 2008;5(9):925-928. doi: http://dx.doi.org/10.1513/pats.200804-033QC

11. Barr RG, Berkowitz EA, Bigazzi F, et al. A combined pulmonaryradiology workshop for visual evaluation of COPD: study design, chest CT findings and concordance with quantitative evaluation. COPD. 2012;9(2):151-159.

doi: http://dx.doi.org/10.3109/15412555.2012.654923

12. Coxson HO, Mayo JR, Behzad H, et al. Measurement of lung expansion with computed tomography and comparison with quantitative histology. J Appl Physiol. 1995;79(5):1525-1530.

13. Gevenois PA, De VP, de M, V et al. Comparison of computed density and microscopic morphometry in pulmonary emphysema. Am J Respir Crit Care Med. 1996;154(1):187-192. doi:http://dx.doi.org/10.1164/ajrccm.154.1.8680679

14. Gould GA, MacNee W, McLean A, et al. CT measurements of lung density in life can quantitate distal airspace enlargement-an essential defining feature of human emphysema. Am Rev Respir Dis. 1988;137(2):380-392.

doi: http://dx.doi.org/10.1164/ajrccm/137.2.380
15. XieX, de Jong PA, Oudkerk M, etal.Morphological measurements in computed tomography correlate with airflow obstruction in chronic obstructive pulmonary disease: systematic review and meta-analysis. Eur Radiol. 2012;22(10):2085-2093. doi: http://dx.doi.org/10.1007/s00330-012-2480-8

16. Muller NL, Staples CA, Miller RR, Abboud RT. Density mask. An objective method to quantitate emphysema using computed tomography. Chest. 1988;94(4):782-787. doi: http://dx.doi.org/10.1378/chest.94.4.782

17. Gould GA, MacNee W, McLean A, et al. CT measurements of lung density in life can quantitate distal airspace enlargement-an essential defining feature of human emphysema. Am Rev Respir Dis. 1988;137(2):380-392. doi:http://dx.doi.org/10.1164/ajrccm/137.2.380

18. Kinsella M, Muller NL, Abboud RT, Morrison NJ, DyBuncio A. Quantitation of emphysema by computed tomography using a "density mask" program and correlation with pulmonary function tests. Chest. 1990;97(2):315-321. doi:http://dx.doi.org/10.1378/chest.97.2.315

19. Gould GA, Redpath AT, Ryan M, et al. Lung CT density correlates with measurements of airflow limitation and the diffusing capacity. Eur Respir J. 1991;4(2):141-146.

20. Gurney JW, Jones KK, Robbins RA, et al. Regional distribution of emphysema: correlation of high-resolution CT with pulmonary function tests in unselected smokers. Radiology. 1992;183(2):457-463. doi: http://dx.doi.org/10.1148/radiology.183.2.1561350

21. Klein JS, Gamsu G, Webb WR, Golden JA, Muller NL. Highresolution $\mathrm{CT}$ diagnosis of emphysema in symptomatic patients with normal chest radiographs and isolated low diffusing capacity. Radiology. 1992;182(3):817-821. doi: http://dx.doi.org/10.1148/radiology.182.3.1535900

22. Nakano Y, Muller NL, King GG, et al. Quantitative assessment of airway remodeling using high-resolution CT. Chest. 2002;122(6 Suppl):271S-275S.

23. Han MK, Kazerooni EA, Lynch DA et al. Chronic obstructive pulmonary disease exacerbations in the COPDGene study: associated radiologic phenotypes. Radiology. 2011;261(1):274282. doi;http://dx.doi.org/10.1148/radiol.11110173

24. Coxson HO, Dirksen A, Edwards LD, et al. The presence and progression of emphysema in COPD as determined by CT scanning and biomarker expression: a prospective analysis from the ECLIPSE study. Lancet Respir Med. 2013;1(2):129-136. doi: http://dx.doi.org/10.1016/S2213-2600(13)70006-7

25. Pedersen JH, Ashraf H, Dirksen A et al. The Danish randomized lung cancer CT screening trial--overall design and results of the prevalence round. J Thorac Oncol. 2009;4(5):608-614. doi: http://dx.doi.org/10.1097/JTO.0b013e3181a0d98f

26. Agusti A, Calverley PM, Celli B, et al. Characterisation of COPD heterogeneity in the ECLIPSE cohort. Respir Res. 2010;11:122.

27. Vestbo J, Anderson W, Coxson HO, et al. Evaluation of COPD Longitudinally to Identify Predictive Surrogate End-points (ECLIPSE). Eur Respir J. 2008;31(4):869-873. doi: http://dx.doi.org/10.1183/09031936.00111707

28. Rabe KF, Hurd S, Anzueto A, et al. Global strategy for the diagnosis, management, and prevention of chronic obstructive pulmonary disease: GOLD executive summary. Am J Respir Crit Care Med. 2007;176(6):532-555. doi: http://dx.doi.org/10.1164/rccm.200703-456SO 
29. Pellegrino R, Viegi G, Brusasco V, et al. Interpretative strategies for lung function tests. Eur Respir J. 2005;26(5):948-968. doi: http://dx.doi.org/10.1183/09031936.05.00035205

30. Lo P, Sporring J, Ashraf H, Pedersen JJ, de BM. Vessel-guided airway tree segmentation: A voxel classification approach. Med Image Anal. 2010;14(4):527-538.

doi: http://dx.doi.org/10.1016/j.media.2010.03.004

31. Gietema HA, Muller NL, Fauerbach PV, et al. Quantifying the extent of emphysema: factors associated with radiologists' estimations and quantitative indices of emphysema severity using the ECLIPSE cohort. Acad Radiol. 2011;18(6):661-671. doi: http://dx.doi.org/10.1016/j.acra.2011.01.011

32. Mohamed Hoesein FA, de HB, Zanen P, et al. CT-quantified emphysema in male heavy smokers: association with lung function decline. Thorax. 2011;66(9):782-787. doi: http://dx.doi.org/10.1136/thx.2010.145995

33. Mohamed Hoesein FA, van RE, van GB, et al. Computed tomography-quantified emphysema distribution is associated with lung function decline. Eur Respir J. 2012;40(4):844-850. doi:http://dx.doi.org/10.1183/09031936.00186311

34. Parr DG, Stoel BC, Stolk J, Stockley RA. Validation of computed tomographic lung densitometry for monitoring emphysema in alpha1-antitrypsin deficiency. Thorax. 2006;61(6):485-490. doi:http://dx.doi.org/10.1136/thx.2005.054890

35. Parr DG, Sevenoaks M, Deng C, Stoel BC, Stockley RA. Detection of emphysema progression in alpha 1-antitrypsin deficiency using CT densitometry; methodological advances. Respir Res. 2008;9:21. doi: http://dx.doi.org/10.1186/1465-9921-9-21

36. 36. Stoel BC, Putter H, Bakker ME, et al. Volume correction in computed tomography densitometry for follow-up studies on pulmonary emphysema. Proc Am Thorac Soc. 2008;5(9):919-924. doi: http://dx.doi.org/10.1513/pats.200804-040QC

37. Coxson HO, Dirksen A, Edwards LD, et al. The presence and progression of emphysema in COPD as determined by CT scanning and biomarker expression: a prospective analysis from the ECLIPSE study. Lancet Respiratory. 2013;1(2):129-136. doi: http://dx.doi.org/10.1016/S2213-2600(13)70006-7

38. Hansell DM, Bankier AA, MacMahon H, McLoud TC, Muller NL, Remy J. Fleischner Society: glossary of terms for thoracic imaging. Radiology. 2008;246(3):697-722. doi: http://dx.doi.org/10.1148/radiol.2462070712

39. Castaldi PJ, Dy J, Ross J, et al. Cluster analysis in the COPDGene study identifies subtypes of smokers with distinct patterns of airway disease and emphysema. Thorax. 2014;69(5):415-422. doi: http://dx.doi.org/10.1136/thoraxjnl-2013-203601

40. Parkes G, Greenhalgh T, Griffin M, Dent R. Effect on smoking quit rate of telling patients their lung age: the Step2quit randomised controlled trial. BMJ. 2008;336(7644):598-600. doi: http://dx.doi.org/10.1136/bmj.39503.582396.25

41. Anderson CM, Yip R, Henschke CI, Yankelevitz DF, Ostroff JS, Burns DM. Smoking cessation and relapse during a lung cancer screening program. Cancer Epidemiol Biomarkers Prev. 2009;18(12):3476-3483.

doi: http://dx.doi.org/10.1158/1055-9965.EPI-09-0176
42. Ostroff JS, Buckshee N, Mancuso CA, Yankelevitz DF, Henschke CI. Smoking cessation following CT screening for early detection of lung cancer. Prev Med. 2001;33(6):613-621. doi: http://dx.doi.org/10.1006/pmed.2001.0935

43. Tammemagi MC, Berg CD, Riley TL, Cunningham CR, Taylor KL. Impact of lung cancer screening results on smoking cessation. J Natl Cancer Inst.2014;106(6):dju084. doi: http://dx.doi.org/10.1093/jnci/dju084

44. Washko GR, Criner GJ, Mohsenifar Z, et al. Computed tomographic-based quantification of emphysema and correlation to pulmonary function and mechanics. COPD. 2008;5(3):177-186. doi: http://dx.doi.org/10.1080/15412550802093025

45. Akira M, Toyokawa K, Inoue Y, Arai T. Quantitative CT in chronic obstructive pulmonary disease: inspiratory and expiratory assessment. AJR Am J Roentgenol. 2009;192(1):267272. doi:http://dx.doi.org/10.2214/AJR.07.3953

46. Heussel CP, Herth FJ, Kappes J, et al. Fully automatic quantitative assessment of emphysema in computed tomography: comparison with pulmonary function testing and normal values. Eur Radio.l 2009;19(10):2391-2402.

http://dx.doi.org/10.1007/s00330-009-1437-z

47. Shaker SB, Maltbaek N, Brand P, Haeussermann S, Dirksen A. Quantitative computed tomography and aerosol morphometry in COPD and alpha1-antitrypsin deficiency. Eur Respir J. 2005;25(1):23-30. doi: http://dx.doi.org/10.1183/09031936.04.00075304

48. Shaker SB, Stavngaard T, Hestad M, Bach KS, Tonnesen P, Dirksen A. The extent of emphysema in patients with COPD. Clin Respir J. 2009;3(1):15-21. doi: http://dx.doi.org/10.1111/j.1752-699X.2008.00102.x

49. Shaker SB, Dirksen A, Lo P, Skovgaard LT, de BM, Pedersen JH. Factors influencing the decline in lung density in a Danish lung cancer screening cohort. Eur Respir J. 2012;40(5):1142-1148. doi:http://dx.doi.org/10.1183/09031936.00207911

50. Shaker SB, Stavngaard T, Laursen LC, Stoel BC, Dirksen A. Rapid fall in lung density following smoking cessation in COPD. COPD. 2011;8(1):2-7. doi: http://dx.doi.org/10.3109/15412555.2010.541306

51. Ashraf H, Lo P, Shaker SB, et al. Short-term effect of changes in smoking behaviour on emphysema quantification by CT. Thorax. 2011;66(1):55-60. doi: http://dx.doi.org/10.1136/thx.2009.132688

52. Shaker SB, Dirksen A, Laursen LC, et al. Short-term reproducibility of computed tomography-based lung density measurements in alpha-1 antitrypsin deficiency and smokers with emphysema. Acta Radiol. 2004;45(4):424-430. doi: http://dx.doi.org/10.1080/02841850410005642 